\title{
The Maillard Reaction as Source of Meat Flavor Compounds in Dry Cured Meat Model Systems under Mild Temperature Conditions
}

\author{
Lei Li, Carmela Belloch and Mónica Flores * (D)
}

check for updates

Citation: Li, L.; Belloch, C.; Flores, M. The Maillard Reaction as Source of Meat Flavor Compounds in Dry Cured Meat Model Systems under Mild Temperature Conditions. Molecules 2021, 26, 223. https://doi.org/10.3390/ molecules 26010223

Academic Editor: Derek J. McPhee Received: 3 December 2020 Accepted: 29 December 2020 Published: 4 January 2021

Publisher's Note: MDPI stays neutral with regard to jurisdictional clai$\mathrm{ms}$ in published maps and institutional affiliations.

Copyright: (C) 2021 by the authors. Licensee MDPI, Basel, Switzerland. This article is an open access article distributed under the terms and conditions of the Creative Commons Attribution (CC BY) license (https:// creativecommons.org/licenses/by/ $4.0 /)$.
Instituto de Agroquímica y Tecnología de Alimentos (IATA-CSIC), Avda. Agustín Escardino 7, 46980 Paterna, Valencia, Spain; leili@iata.csic.es (L.L.); belloch@iata.csic.es (C.B.)

* Correspondence: mflores@iata.csic.es; Tel.: +34-96-3900022

\begin{abstract}
Flavor is amongst the major personal satisfaction indicators for meat products. The aroma of dry cured meat products is generated under specific conditions such as long ripening periods and mild temperatures. In these conditions, the contribution of Maillard reactions to the generation of the dry cured flavor is unknown. The main purpose of this study was to examine mild curing conditions such as temperature, $\mathrm{pH}$ and $\mathrm{a}_{\mathrm{w}}$ for the generation of volatile compounds responsible for the cured meat aroma in model systems simulating dry fermented sausages. The different conditions were tested in model systems resembling dry fermented sausages at different stages of production. Three conditions of model system, labeled initial (I), 1st drying (1D) and 2nd drying (2D) and containing different concentrations of amino acid and curing additives, as well as different $\mathrm{pH}$ and $\mathrm{a}_{\mathrm{w}}$ values, were incubated at different temperatures. Changes in the profile of the volatile compounds were investigated by solid phase microextraction and gas chromatography mass spectrometry (SPMEGS-MS) as well as the amino acid content. Seventeen volatile compounds were identified and quantified in the model systems. A significant production of branched chain volatile compounds, sulfur, furans, pyrazines and heterocyclic volatile compounds were detected in the model systems. At the drying stages, temperature was the main factor affecting volatile production, followed by amino acid concentration and $\mathrm{a}_{\mathrm{w}}$. This research demonstrates that at the mild curing conditions used to produce dry cured meat product volatile compounds are generated via the Maillard reaction from free amino acids. Moreover, in these conditions $\mathrm{a}_{\mathrm{w}}$ plays an important role promoting formation of flavor compounds.
\end{abstract}

Keywords: meat flavor; dry cured; mild conditions

\section{Introduction}

Flavor is among the most important quality indicators of meat products. Flavor compounds produced during the processing of meat products are generated through different mechanisms including the Maillard reaction, Strecker degradation, lipid oxidative reactions, degradation of thiamine, ribonucleotides and carbohydrates, as well as microbial metabolism [1,2]. The contribution of these reactions to meat flavor depends on the manufacture conditions applied during processing.

Flavor compounds present in cooked cured meat products have been studied qualitatively and quantitatively [3], the Maillard reaction being the most important reaction for the production of meaty aroma compounds [4]. The Maillard reaction between an amino group and a reducing sugar is commonly divided into three stages: Amadori/Heyns rearrangement, sugar fragmentation and retro-aldolization. In these reactions the free amino group of amino acids peptides or proteins participates in dehydration, fragmentation, cyclization and polymerization reactions. The different paths involved in the Maillard reaction depend on conditions such as temperature, $\mathrm{pH}$ and water content that regulate the reaction kinetics, 
and type of sugar and amino acids that modulate the flavor compounds formed [5]. Extensive investigation of flavor formation in cooked cured meat products [6] has revealed the effect of cooking temperature, amino acid and sugar types and lipid composition [7]. Meaty aroma seems to be constituted by different volatile compounds, although the contribution of sulfur-containing compounds is essential [1]. Among these, thiophenes are derived mainly from the Maillard reaction between cysteine and ribose [5]. Amino acids such as cysteine and glycine are of utmost importance as precursors of sulfur-containing meaty compounds [8,9]. Furthermore, meat post-mortem conditioning increases the formation of Maillard reaction-derived meaty flavor compounds by the presence of ribose, methionine and cysteine [10].

Few studies have focused on the role of Maillard kinetics for flavor generation during dry cured meat processing. In these types of products, low temperatures are applied during long processing times depending on products, ranging between 2 to 3 months in dry fermented sausages, and up to 2-3 years in dry cured hams [11]. Flavor production during dry cured meat processing is influenced by the use salt and nitrate and/or nitrite, which are rubbed on the surface of meat or mixed with the minced meat. As a result of the proteolysis occurring during dry curing, there is an increase in free amino acids which are flavor precursors in dry cured meat products [12]. Both $\mathrm{pH}$ and $\mathrm{a}_{\mathrm{w}}$ exert a profound influence on the abundance of meaty flavor compounds in thermal treatments [13]. However, flavor composition of dry cured meat products and cooked cured meat products is significantly different due to the different processing methods [1]. The meaty flavor compounds of dry cured meat products are produced under long ripening periods where mild temperatures are applied.

The mechanisms involved in the generation of meaty flavor compounds in dry fermented sausages and the influence of the physicochemical conditions such as $\mathrm{pH}$ and low temperature are poorly understood, whereas many studies have focused on the microbial contribution during fermentation [14,15]. Additionally, several studies have focused on the lipid oxidation effect on dry sausage flavor [16]. However, the role of Maillard reactions in dry sausage flavor generation has not been elucidated. The control of flavor formation in meat products from Maillard reactions is essential for flavor quality [17]. Therefore, new studies on Maillard reactions are necessary to identify the influence of critical process parameters $\left(\mathrm{pH}\right.$, temperature, $\left.\mathrm{a}_{\mathrm{w}}\right)$ as well as determine the effect of reactant concentrations on the formation of flavor compounds in dry cured meat products.

The main purpose of this study was to examine mild curing conditions as far as temperature, $\mathrm{pH}$ and $\mathrm{a}_{\mathrm{w}}$ for the generation of volatile compounds responsible for the cured meat aroma in model systems simulating dry fermented sausages. Model systems characterized by different amino acid and additive composition were incubated at 25 and $37^{\circ} \mathrm{C}$ and samples taken at different times for profiling of generated volatile compounds and amino acid content.

\section{Results}

\subsection{Analysis of Physicochemical Changes in the Model Systems}

Water activity $\left(\mathrm{a}_{\mathrm{w}}\right)$ and $\mathrm{pH}$ (Figures S1 and S2 Supplementary Material, respectively) were measured during the incubation of sausage model systems (media I, 1D and 2D) at mild conditions $\left(25\right.$ and $37^{\circ} \mathrm{C}$ ), and both parameters remained stable from the first day of incubation until $35 \mathrm{~d}$.

\subsection{Identification of Volatile Compounds Generated in the Model Systems}

The identification of volatile compounds generated in the model systems is listed in Table 1. Seventeen volatile compounds were identified, and 1 of them (furan) was only tentatively identified. The compounds identified belonged to different chemical classes: 2 ketones, 2 furans, 6 aldehydes, 1 sulfur compounds, 1 pyrazine, 1 alcohol, 1 acid and 3 hydrocarbons. Not all compounds were detected in the three models. Furan, dimethyl disulfide, thiazole and methyl-pyrazine were absent in model I at both temperature condi- 
tions. Additionally, furfural was only detected when the three models were incubated at $37^{\circ} \mathrm{C}$. The volatile compounds detected were mainly derived from branched chain amino acids (Val, Leu and Ile); sulfur amino acids (Met and Cys); and Phe, Ala, Thr and Ser.

Table 1. Volatile compounds identified in the model systems.

\begin{tabular}{|c|c|c|c|c|c|c|c|c|c|c|c|c|}
\hline \multirow{2}{*}{ Compound } & \multirow{2}{*}{ LRI $^{1}$} & \multirow{2}{*}{ LRI std ${ }^{2}$} & \multirow{2}{*}{$\mathrm{RI}^{3}$} & \multicolumn{2}{|c|}{ Initial Stage } & \multicolumn{2}{|c|}{ 1st Drying Stage } & \multicolumn{2}{|c|}{ 2nd Drying Stage } & \multirow{2}{*}{$\underset{\text { Precursor } 5}{\text { Aac }}$} & \multirow{2}{*}{ Odor 6} & \multirow{2}{*}{$\underset{(\mathrm{mg} / \mathrm{kg})^{7}}{\text { Threshold in }}$} \\
\hline & & & & $\mathrm{I}-25^{\circ}$ & $\mathrm{I}-37^{\circ}$ & $1 \mathrm{D}-25^{\circ}$ & $1 \mathrm{D}-37^{\circ}$ & $2 \mathrm{D}-25^{\circ}$ & $2 \mathrm{D}-37^{\circ}$ & & & \\
\hline Furan & 514 & & b & & & +4 & + & + & + & Ala, Thr, Ser [18] & ethereal & $4.5-6$ a \\
\hline Acetone & 530 & 527 & a & + & + & + & + & + & + & & ethereal & 100-1000 \\
\hline 2-Methylpropanal & 594 & 590 & a & + & + & + & + & + & + & Val [19] & pungent, floral & 0.043 \\
\hline 2-Butanone & 632 & 629 & a & & + & + & + & + & + & & woody, yogurt & $10-100$ \\
\hline 3-Methylbutanal & 692 & 687 & a & + & + & + & + & + & + & Leu [19] & fruity green cocoa & $0.0054-0.013$ \\
\hline Heptane & 700 & 700 & a & + & + & + & + & + & + & & & \\
\hline 2-Methylbutanal & 702 & 698 & a & + & + & + & + & + & + & Ile [19] & $\begin{array}{l}\text { musty chocolate, } \\
\text { malty }\end{array}$ & $0.0022-0.152$ \\
\hline Acetic acid & 715 & 714 & a & + & + & + & + & + & + & & pungent vinegar & $0.12-0.75$ \\
\hline Dimethyl disulfide & 773 & 774 & a & & & + & + & + & + & Met [20] & onion, cabbage & 0.012 \\
\hline Thiazole & 776 & 776 & a & & & + & + & + & + & Cys [21] & nutty, meaty & $0.038-3.1^{\mathrm{a}}$ \\
\hline Methylpyrazine & 860 & 860 & a & & & + & + & + & + & Gly, Lys, Cys $[22,23]$ & nutty, cocoa, roasted, & 27 \\
\hline$p$-xylene & 892 & 893 & a & + & + & + & + & + & + & & - & \\
\hline Furfural & 898 & 898 & a & & + & & + & & + & & $\begin{array}{l}\text { brown, bready, nutty, } \\
\text { caramel }\end{array}$ & $155^{\mathrm{b}}$ \\
\hline $\begin{array}{l}\text { 3- } \\
\text { (Methylthio)propanal }\end{array}$ & 968 & 968 & a & + & + & + & + & + & + & Met [24] & $\begin{array}{l}\text { cooked potato, } \\
\text { onion, }\end{array}$ & 0.0002 \\
\hline Benzaldehyde & 1020 & 1013 & a & + & + & + & + & + & + & Phe [25] & $\begin{array}{l}\text { bitter almond, } \\
\text { cherry }\end{array}$ & 0.06 \\
\hline 2-Ethyl-1-hexanol & 1083 & 1083 & a & + & + & + & + & + & + & & sweet, fatty, fruity & $0.27-25^{\mathrm{a}}$ \\
\hline Benzeneacetaldehyde & 1110 & 1104 & a & + & + & + & + & + & + & Phe [26] & floral, chocolate & $0.002-0.03$ a \\
\hline
\end{tabular}

${ }^{1}$ LRI: Linear retention indices of the compounds eluted from the GC-MS using a DB-624 capillary column. ${ }^{2}$ LRI std: Linear Retention Indices of authentic standard compounds. ${ }^{3}$ RI: Reliability of identification: a: identification by mass spectrum and coincident with LRI of an authentic standard; b: tentative identification by mass spectrum. ${ }^{4}$ Blank space means not generated; + indicates the compound was detected. ${ }^{5}$ Bibliographic references indicating the amino acid precursor of the volatile compound are between brackets. ${ }^{6}$ Burdok, G.A. (2010). Fenaroli's handbook of flavor ingredients (6th ed.). Florida: Boca Raton. CRC Press Inc. ${ }^{7}$ Van Gemert, L., and Nettenbreijer, A. (2011). Compilation of odor threshold values in air, water and other media. The Netherlands: BACIS: Zeist. ${ }^{a}$ Threshold reported in water; $\mathrm{b}$ threshold reported in propylenglycol.

\subsection{Quantitation of Volatile Compounds Generated in the Model Systems}

The quantitation of all the volatile compounds generated in the model systems incubated at 25 and $37^{\circ} \mathrm{C}$ is shown in Tables S1 and S2 of Supplementary Material. Figures 1-3 show the changes in abundance of the most variable volatile compounds derived from branched-chain amino acids Val, Leu and Ile (Figure 1); sulfur amino acids (Met and Cys) and Phe (Figure 2); and heterocyclic compounds (Figure 3).

Figure 1 shows that model system I (Figure 1a,d) was very poor in volatile compounds derived from Val, Ile and Leu at both incubation temperatures and any time. Model 1D (Figure $1 \mathrm{~b}, \mathrm{e})$ showed a significant $(p<0.001)$ increase in the content of 3-methylbutanal during the incubation time. This increase was even higher when the model system was incubated at $37^{\circ} \mathrm{C}$. A similar trend was also observed in the case of 2-methylbutanal, although this compound was produced in lower amounts. In model 2D (Figure 1c,f), the evolution of 3-methylbutanal and 2-methylbutanal was similar than in model 1D, but the changes were significantly higher $(p<0.001)$ when the model system was incubated at $37^{\circ} \mathrm{C}$.

In Figure 2, the changes observed in the volatile compounds in model system I (Figure 2a,d) were not significant at any incubation temperature or time. On the contrary, model systems 1D and 2D showed a significant $(p<0.001)$ increase in benzaldehyde and benzeneacetaldehyde during the incubation time and, as in Figure 1, this increase was significantly higher at $37^{\circ} \mathrm{C}$ (Figure $2 \mathrm{~b}, \mathrm{c}$ vs. 2e,f). Dimethyl disulfide was detected depending on the temperature and time of incubation. At $25^{\circ} \mathrm{C}$, it was detected at the end of incubation time ( $35 \mathrm{~d}$ ) (Figure $2 \mathrm{~b}, \mathrm{c}$ ), whilst at $37^{\circ} \mathrm{C}$, it was detected at 15 (2D) or $20 \mathrm{~d}$ (1D) of incubation time (Figure 2e,f). The abundance of this compound increased with the incubation time. Moreover, 3-(methythio)propanal was detected in higher abundance at $37^{\circ}$ (Figure 2f) than at $25^{\circ} \mathrm{C}$ (Figure $2 \mathrm{~b}, \mathrm{c}$ ), although in both conditions it increased until $10-15 \mathrm{~d}$ but showed a small decrease afterwards. 
(a)

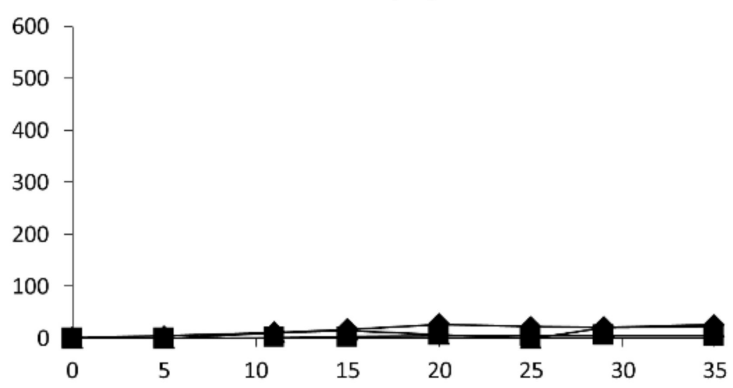

(b)

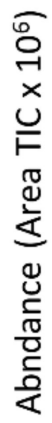

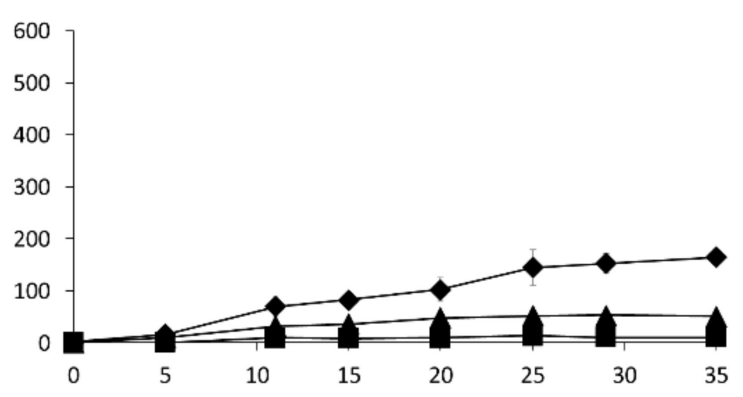

(c)

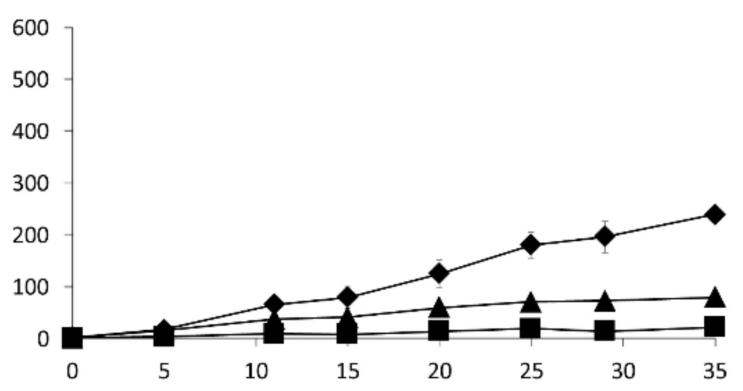

(d)

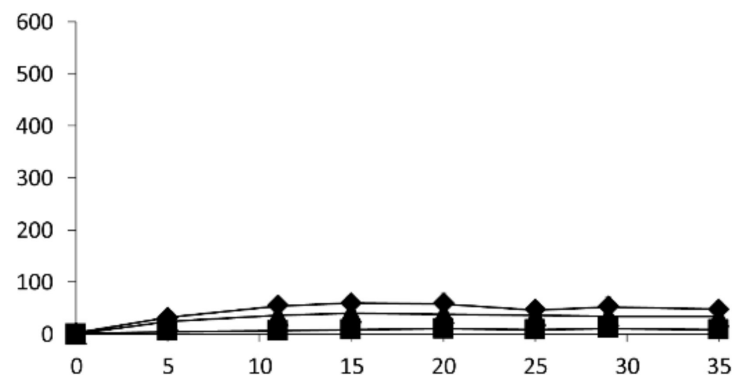

(e)

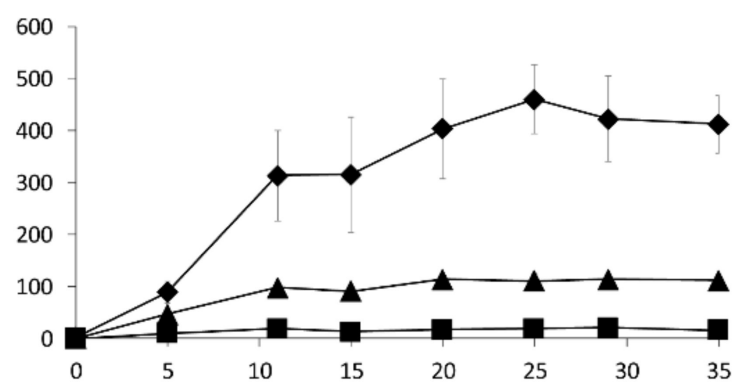

(f)

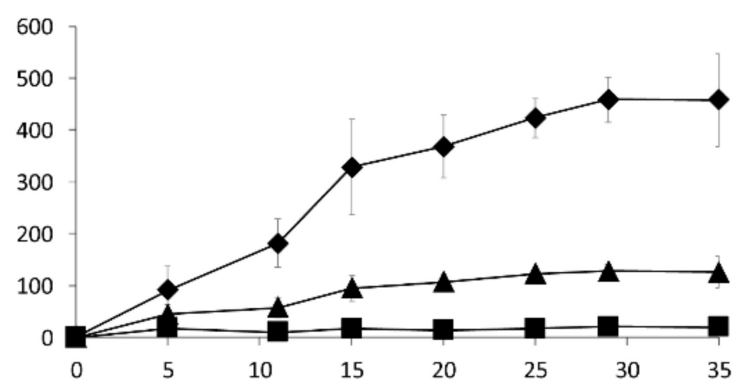

Time (days)

Figure 1. Abundance of volatile compounds derived from Val, Ile and Leu in the model systems during incubation at 25 or $37^{\circ} \mathrm{C}$ and classified according to the dry curing stages (I-Initial stage, 1D-1st drying stage, 2D-2nd drying stage). (a) $\mathrm{I}-25{ }^{\circ} \mathrm{C}$, (b) $1 \mathrm{D}-25{ }^{\circ} \mathrm{C}$, (c) $2 \mathrm{D}-25{ }^{\circ} \mathrm{C}$, (d) I-37 ${ }^{\circ} \mathrm{C}$, (e) $1 \mathrm{D}-37^{\circ} \mathrm{C}$, (f) $2 \mathrm{D}-37^{\circ} \mathrm{C}$. Symbols represent the different compounds:

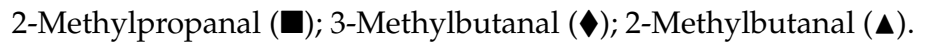


(a)

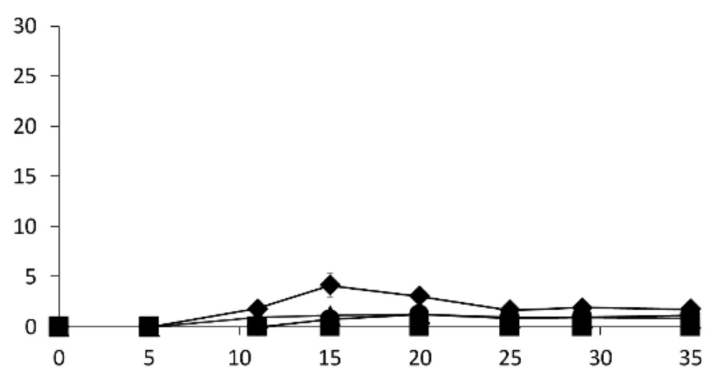

(b)

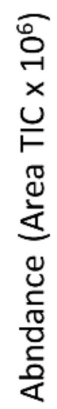

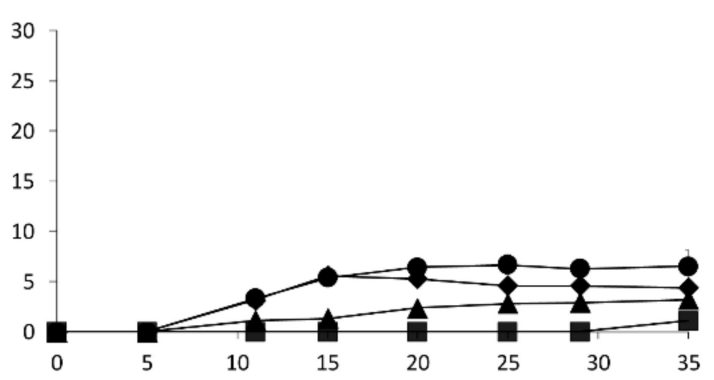

(c)

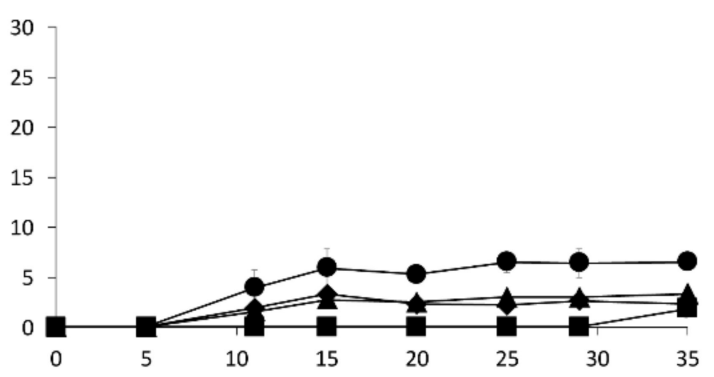

(d)

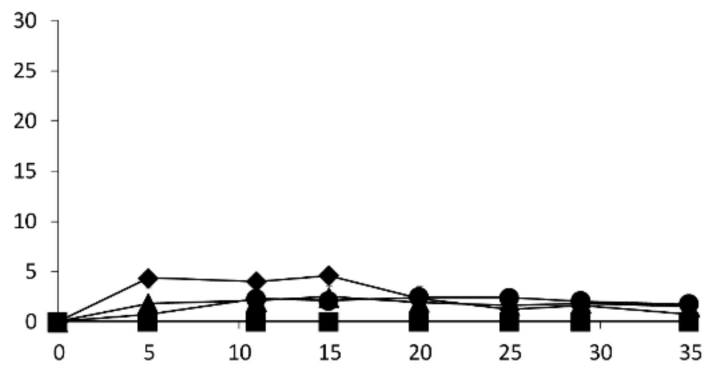

(e)

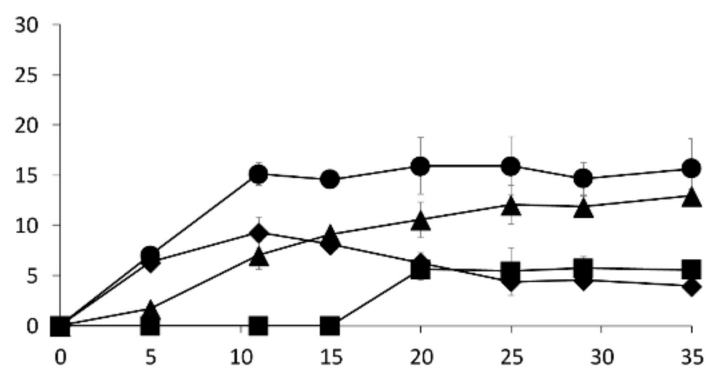

(f)

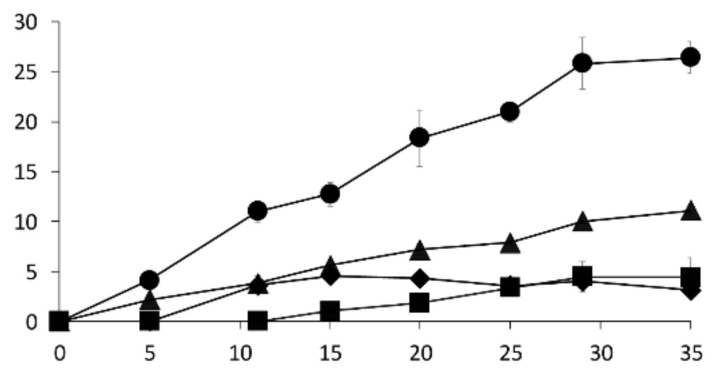

Time (days)

Figure 2. Abundance of volatile compounds derived from sulfur amino acids and Phe in the model systems during incubation at 25 or $37^{\circ} \mathrm{C}$ and classified according to the dry curing stages (I-Initial stage, 1D-1st drying stage, 2D-2nd drying stage). (a) I- $25{ }^{\circ} \mathrm{C}$, (b) $1 \mathrm{D}-25^{\circ} \mathrm{C}$, (c) $2 \mathrm{D}-25^{\circ} \mathrm{C}$, (d) I-37 ${ }^{\circ} \mathrm{C},(\mathbf{e}) 1 \mathrm{D}-37^{\circ} \mathrm{C}$, (f) $2 \mathrm{D}-37^{\circ} \mathrm{C}$. Symbols represent the different

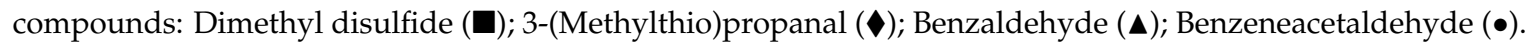


(a)

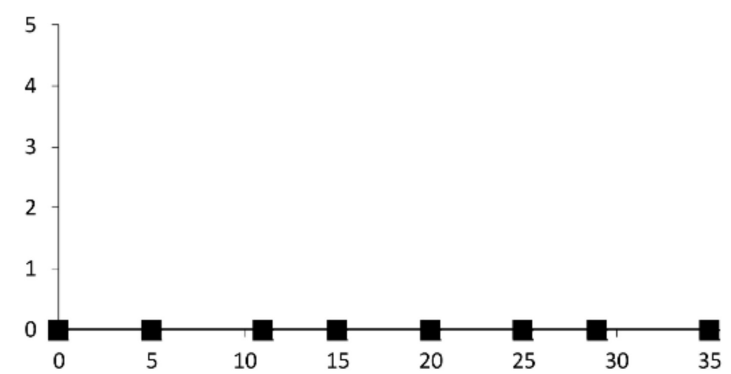

(b)

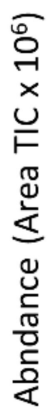

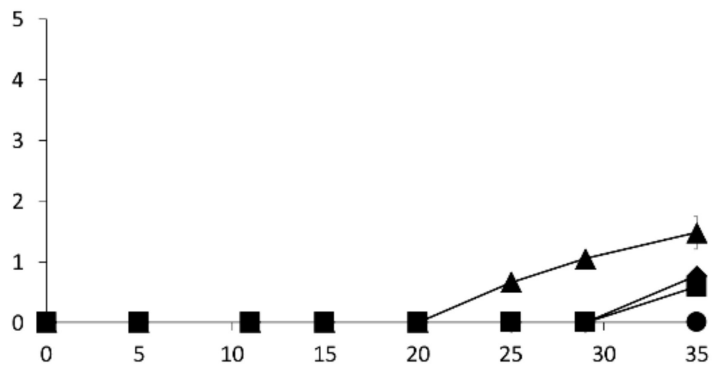

(c)

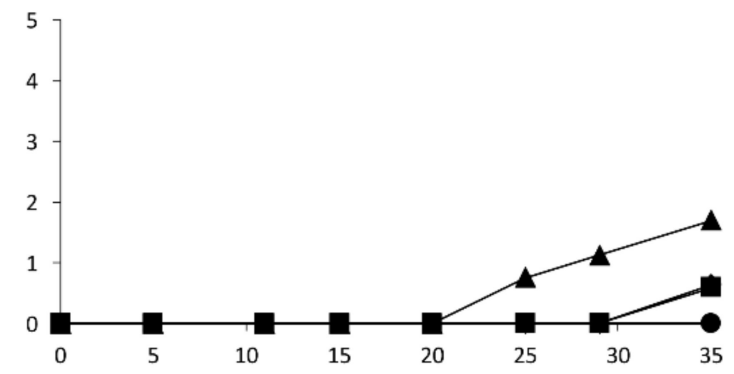

(d)

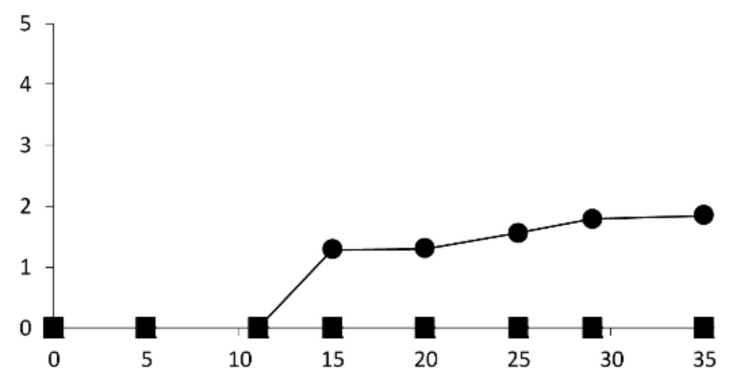

(e)

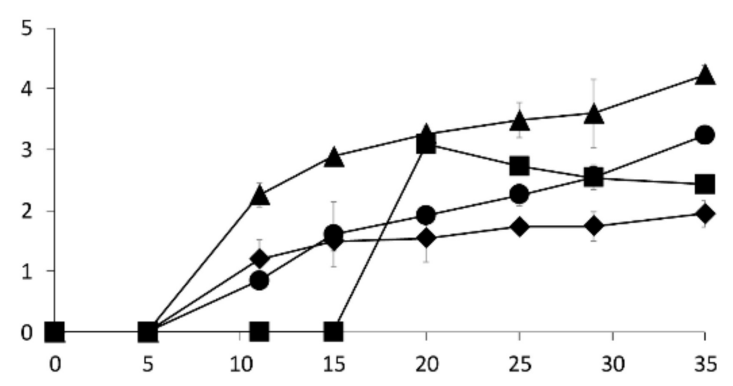

(f)

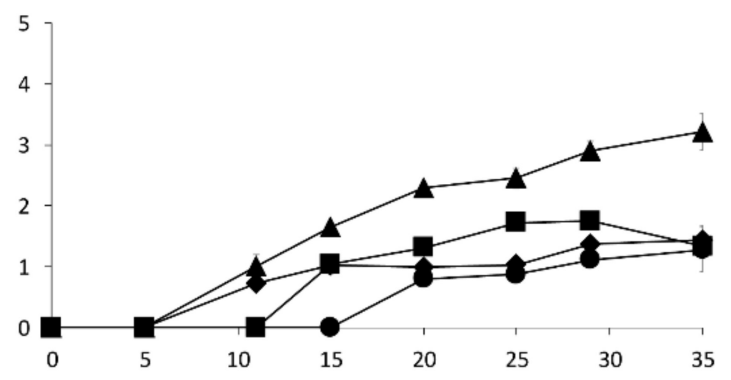

Time (days)

Figure 3. Abundance of heterocyclic volatile compounds derived from other amino acids in the model systems during incubation at 25 or $37^{\circ} \mathrm{C}$ and classified according to the dry curing stages (I-Initial stage, 1D-1st drying stage, 2D-2nd drying stage). (a) I-25 ${ }^{\circ} \mathrm{C}$, (b) $1 \mathrm{D}-25^{\circ} \mathrm{C}$, (c) $2 \mathrm{D}-25^{\circ} \mathrm{C}$, (d) I- $37^{\circ} \mathrm{C}$, (e) $1 \mathrm{D}-37^{\circ} \mathrm{C}$, (f) $2 \mathrm{D}-37^{\circ} \mathrm{C}$. Symbols represent the different compound: Furan $(\mathbf{\square})$; Thiazole $(\diamond)$; Methylpyrazine $(\boldsymbol{\Delta})$; Furfural $(\bullet)$.

In Figure 3, we can observe an increase in furfural in model system I at $37{ }^{\circ} \mathrm{C}$ (Figure 3a,d). In model systems 1D and 2D (Figure 3b,e; Figure 3c,f), methylpyrazine, thiazole, furan and furfural increased significantly $(p<0.001)$ during the incubation time, although this increase was significantly higher when the models were incubated at $37^{\circ} \mathrm{C}$.

In order to examine the relationship between the different volatile profiles in the model systems under mild conditions $\left(25\right.$ and $\left.37^{\circ} \mathrm{C}\right)$ and the flavor compounds produced, a principal component analysis (PCA) was performed (Figure 4). Two principal components were able to explain the $75.93 \%$ of the total variability. PC1 accounts for $62.25 \%$ of the variability and was strongly related with the incubation time. Model I, characterized by short incubation times, was located on the left quadrant, while model systems 1D and 2D, incubated for longer times, were on the right. This would indicate that PC1 takes into account model system composition and incubation time. PC2 accounts for $13.88 \%$ of the variability and distinguishes samples by different groups of flavor compounds. Most of the aldehydes and ketones were on the upper quadrants, whereas on the lower quadrants, furans (furan and furfural), cyclic compounds (methylpyrazine and thiazole) and phenyl 
compounds (benzaldehyde) were related to models $1 \mathrm{D}$ and $2 \mathrm{D}$ incubated at $37^{\circ} \mathrm{C}$ during longer times.

Biplot (axes F1 and F2: $75.93 \%$ )

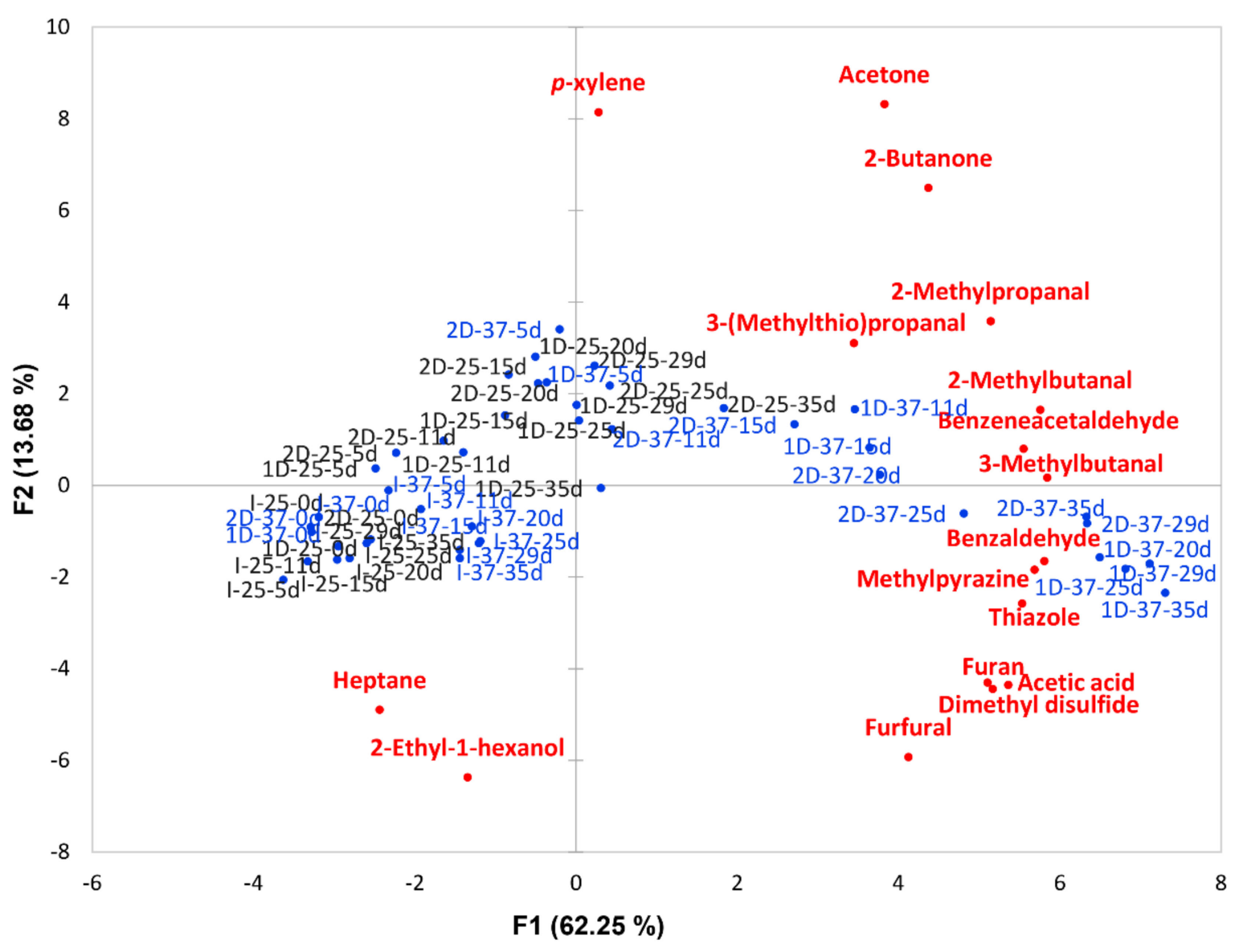

Figure 4. Loadings of the first two principal components (PC1-PC2) representing the variability (volatile compounds) in the model systems simulating the dry curing stages (I-Initial stage, 1D-1st drying stage, 2D-2nd drying stage). Sample loadings in black and blue represent models incubated at 25 and $37^{\circ} \mathrm{C}$, respectively.

\subsection{Amino Acid Concentration in the Model Systems}

The concentration of amino acids was compared among the model systems during the incubation time (Table S3 Supplementary Material). Due to limitations of the analysis method, two amino acids, Arg and Cys, were not analyzed. The concentrations of the amino acids (Val, Leu, Ile, Pro, Met, Phe and orn) during the incubation times (0 to $35 \mathrm{~d}$ ) and temperatures $\left(25\right.$ and $\left.37^{\circ}\right)$ in the different models (I, $1 \mathrm{D}$ and 2D) are shown in Figure 5. Amino acid concentration in model system I did not show significant differences due to incubation times at any temperatures 25 or $37^{\circ} \mathrm{C}$ (Figure $5 \mathrm{a}, \mathrm{d}$ ). On the other hand, a significant $(p<0.001)$ decrease in met during the incubation time was observed in models $1 \mathrm{D}$ and $2 \mathrm{D}$ (Figure 5b,c and Figure 5e,f) at both temperatures. 
(a)

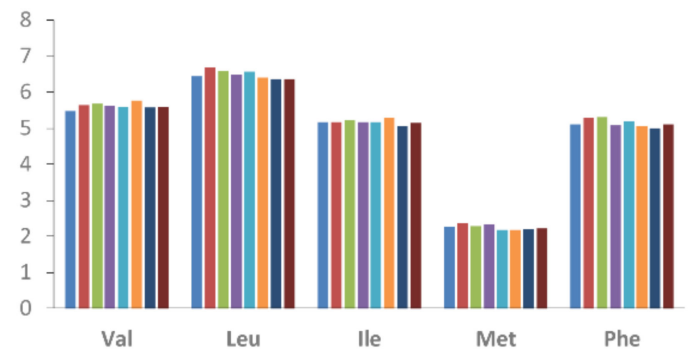

(b)

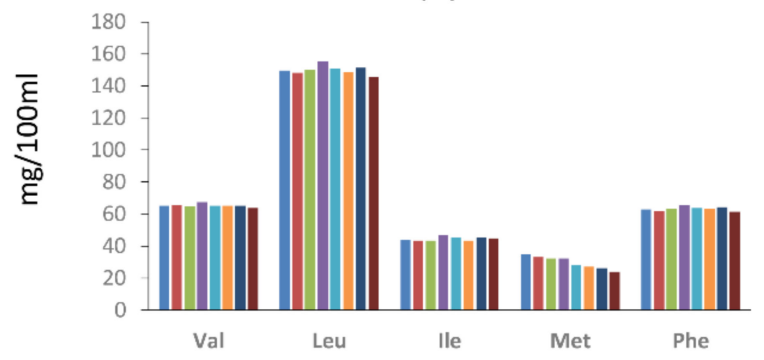

(c)

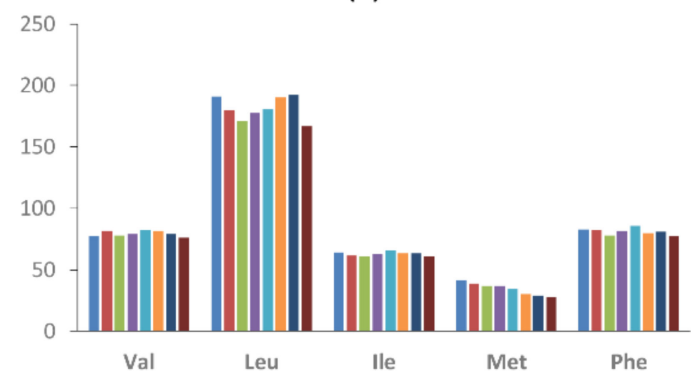

(d)

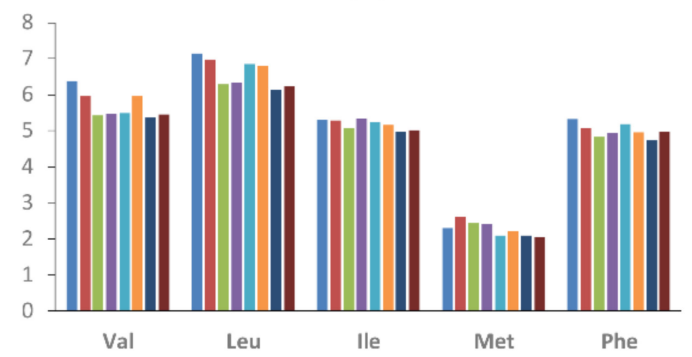

(e)

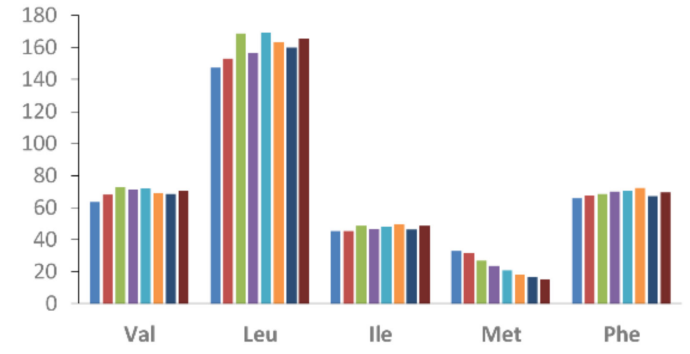

(f)

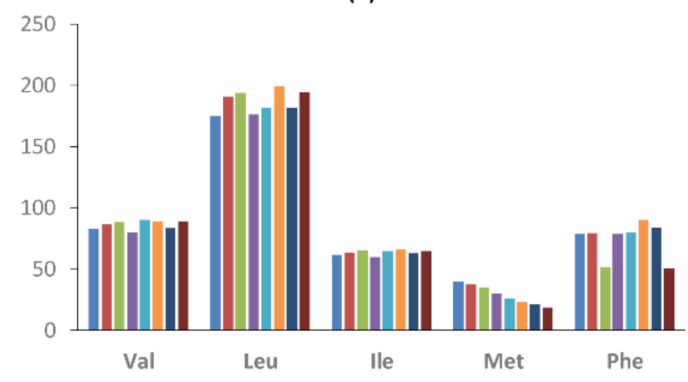

Figure 5. Amino acid concentration in the model systems $(\mathrm{mg} / 100 \mathrm{~mL})$ during incubation at 25 or $37^{\circ} \mathrm{C}$ and classified according to the dry curing stages (I-Initial stage, 1D-1st drying stage, $2 \mathrm{D}-2$ nd drying stage). (a) $\mathrm{I}-25^{\circ} \mathrm{C},(\mathbf{b}) 1 \mathrm{D}-25^{\circ} \mathrm{C}$, (c) $2 \mathrm{D}-25^{\circ} \mathrm{C}$, (d) $\mathrm{I}-37^{\circ} \mathrm{C}$, (e) $1 \mathrm{D}-37^{\circ} \mathrm{C}$, (f) $2 \mathrm{D}-37^{\circ} \mathrm{C}$. Bars from right to left in each amino acid represent concentrations at 0 , $5,9,11$ until $35 \mathrm{~d}$.

\section{Discussion}

Flavor formation in dry cured meat products is very complex because many processing conditions affect its generation [1]. For example, Zamora and Hidalgo [27] indicated the importance of lipid oxidation and Maillard reactions in food processing, and indicated that both reactions are interrelated and the products of each reaction can modify the other.

The results from our experiments demonstrated that model systems that simulate the intermediate processing stages of dry fermented sausages, $1 \mathrm{D}$ and 2D, have different volatile profiles than the model simulating the initial conditions (model I) (Table 2). The conditions in model I were not sufficient to promote Maillard reactions and formation of volatile compounds, because only furfural was detected at $37^{\circ} \mathrm{C}$ (Figure 3). This would indicate that whilst amino acids were present in model I, higher concentrations of amino acids (10 times more) are necessary for volatile generation, as occurs in models 1D and 2D (Figure 5 and Table S3). Therefore, the proteolytic activity occurring during the drying process is essential to the release of free amino acids [12,14] and generation of Maillard reaction products under mild conditions. Moreover, the results showed that formation of Maillard volatile compounds in models 1D and 2D was compound-specific and dependent on the physicochemical conditions $\left(\mathrm{pH}, \mathrm{a}_{\mathrm{w}}\right.$, temperature).

The compounds derived from Val, Leu and Ile were produced in 1D and 2D models and dependent on the concentration of these amino acids in the models. The compound 
produced in the highest quantity 3-methylbutanal was derived from Leu, which was at the highest concentration (Figure 5). Compound 2-methylpropanal appeared always in low amounts (Figure 1) and was not affected by the mild conditions ( $\mathrm{pH}, \mathrm{a}_{\mathrm{w}}$ and temperature) or concentration of precursor Val (Figure 5). The most probable explanation for the generation of this compound in fermented sausages is its production by the activity of Micrococcaceae such as Staphylococcus [28] and not from Maillard reactions. The increase in 3-methylbutanal with the incubation time in models $1 \mathrm{D}$ and $2 \mathrm{D}$, which could be related to the amino acid content and favored by the lowest $\mathrm{a}_{\mathrm{w}}$ in 2D (Figure S1). Previous studies have pointed out that Strecker aldehydes reach a maximum at high temperatures because they are not end products and, therefore, can react further to form other compounds [29]. Similarly, 3-methylbutanal in model $1 \mathrm{D}$ at $37^{\circ} \mathrm{C}$ reached its highest value at 25 days and afterwards decreased. Moreover, $\mathrm{a}_{\mathrm{w}}$ seems to be an essential parameter in Maillard reactions [30], as maximum reaction rates were found at $0.6-0.8 \mathrm{a}_{\mathrm{w}}$ values [31]. These branched aldehydes have been identified as key aroma compounds in dry-cured fermented sausages due to their aroma notes and low thresholds (Table 1) [32]. Similar dynamics were found for 2-methylbutanal generation in models 1D and 2D; however, the low Ile concentration (Figure 5) would have prevented higher production of this compound. In summary, a high amino acid content favored the production of branched aldehydes, the production of which further increased under low $\mathrm{a}_{\mathrm{w}}$. On the other hand, $\mathrm{pH}$ was revealed as an important factor in Maillard reactions [17], affecting the volatile compounds generated [22] even at the small differences observed between 1D and 2D models (0.2 units).

Dimethyl disulfide and 3-(methylthio)propanal generation was related to the Strecker degradation of the amino acid Met (Table 1). The dynamic of 3-(methylthio)propanal generation was different from other volatile compounds produced in the three models. The concentration of this compound increased with incubation time until 10 to $15 \mathrm{~d}$ and then decreased specially in 1D followed by 2D and I model systems. This decrease could be related to an oxidative chemical reaction from L-methionine as observed in other studies [33]. Met in models 1D and 2D favored the generation of 3-(methylthio)propanal versus dimethyl disulfide (Figure 2e,f). Met content was very similar in 1D and 2D (Figure 5), showing a significant decrease during incubation which was more pronounced at $37^{\circ} \mathrm{C}$, in agreement with the higher generation of volatiles at this temperature (Figure 5). This demonstrated that temperature was a key factor in the formation of volatile compounds from Met, but the low temperature applied during dry cured meat processing (ranging from 10 to $25^{\circ} \mathrm{C}$ depending on the ripening stage [11]) does not favor their generation. Regarding $\mathrm{pH}$ and $\mathrm{a}_{\mathrm{w}}$ conditions, model 1D at lower $\mathrm{pH}$ and higher $\mathrm{a}_{\mathrm{w}}$ than $2 \mathrm{D}$ favored the formation of dimethyl disulfide and 3-(methylthio)propanal. Therefore, the lowest $\mathrm{pH}$ values in 1D seemed to favor formation of these compounds, as observed in Maillard models submitted to high cooking temperatures [22]. Additionally, Phe concentration in models $1 \mathrm{D}$ and $2 \mathrm{D}$ together with $37^{\circ} \mathrm{C}$ temperature seemed to be the most important factor for volatile production, although the lower $\mathrm{a}_{\mathrm{w}}$ in 2D (Figure S1) produced a significant effect.

Furan is generated by two major formation pathways: (1) the intact sugar skeleton and (2) recombination of reactive C2 and/or C3 fragments which come from the amino acids Ala, Thr or Ser [18]. In the model systems, furan formation was specially favored by high temperature as observed in models incubated at $37^{\circ} \mathrm{C}$. Concentration of Ala and Thr was higher in 2D than 1D, although the higher Ser content in 1D may have favored furan production in this model (Table S3 Supplementary Material). Furfural appeared to be an intermediate of the Maillard reaction, and its concentration increased with temperature and time (Figure 3). Furfural was the only compound detected in I model, which contained the highest glucose concentration (Table 3). Furfural has been detected as a major product in model systems related to sugar degradation in Maillard reactions and its formation has been related with low $\mathrm{pH}$ values $(\mathrm{pH}<7.0)$ [31]. In models $1 \mathrm{D}$ and $2 \mathrm{D}$, where glucose was low in comparison to I model, furfural formation was favored by the lowest $\mathrm{pH}(4.3)$ value in 1D model. 
Generation of methylpyrazine exclusively in $2 \mathrm{D}$ and $1 \mathrm{D}$ at 25 and $37^{\circ} \mathrm{C}$ was favored by the presence of Lys and high $\mathrm{pH}$ values [22,23]. Methylpyrazine content was the highest in model 1D, although Lys was in higher quantity in model 2D. This would indicate that in addition to Lys other factors affect the generation of this compound.

Other volatile compounds produced in the model systems such as acetic acid and thiazole were also produced in higher quantities in models incubated at $37^{\circ} \mathrm{C}$ than at $25^{\circ} \mathrm{C}$ (Table S3 Supplementary Material). Acetic acid (Table 1), an indicator of the progress of Maillard reaction [34], was identified as byproduct of sugar degradation [18]. Thiazole, a reaction product between cysteine and carbonyls [21], was only generated in models $2 \mathrm{D}$ and $1 \mathrm{D}$ at $37^{\circ} \mathrm{C}$; therefore, temperature seems to be a key factor in the formation of this compound.

This study demonstrates that mild processing conditions such as low temperatures $\left(25\right.$ and $\left.37^{\circ} \mathrm{C}\right), \mathrm{pH}$ and $\mathrm{a}_{\mathrm{w}}$ can be responsible for the different volatile profiles found in the model systems. These mild conditions applied during dry curing show that different aroma compounds can be generated by $\alpha$-dicarbonyl compounds and amino acids as reported in wine aging [35]. In dry meat products, $\mathrm{Zhu}$ [36] evaluated the reactions between glucose and acetaldehyde with histidine and lysine in the generation of meat flavor compounds under mild conditions. These authors observed that histidine and lysine were key precursors of Maillard reaction products that constitute the specific flavor of Jinhua ham. The results obtained with the model systems revealed a higher number of volatile compounds such as pyrazines, furan and sulfur compounds, not found in previous experiments [36] due to the limited number of amino acids and carbonyl compounds.

Another important result of our study is that high glucose content seems not essential for the generation of Maillard reaction volatile compounds, because the four times higher concentration of this compound in model I with respect to models 1D and 2D only resulted in the generation of furfural. Sugar content in dry fermented products decreases during the fermentation stage as it is used by the microorganisms to produce a decline in $\mathrm{pH}$ that favors sausage drying. However, although the nature and content of saccharides has been described as essential in Maillard reactions [31], in dry meat processes, it seems that the limiting factor to produce volatile compounds from Maillard reactions is the amino acid content as well as temperature and $\mathrm{a}_{\mathrm{w}}$ conditions.

The contribution of the volatile compounds to the aroma of the dry cured products is a balance among all the volatile compounds identified in the product [1]. Nevertheless, taking into consideration that the compounds contributing to the aroma, such as 2-methylpropanal, 2 and 3-methylbutanal, 3-(methylthio)propanal, benzaldehyde, benzeneacetaldehyde, dimethyl disulfide and thiazole (Table 1), have the lowest threshold values in oil, they can be considered important contributors to the aroma in dry sausages [37-39]. Moreover, generation of these aroma compounds was mainly observed at long incubation times at mild temperatures in models 1D and 2D indicating the key impact of temperature on aroma formation in dry meat processes.

\section{Materials and Methods}

The different dry cured meat model systems were prepared according to the dry fermented sausages composition $[40,41]$ regarding the concentration of additives and free amino acids at the initial (I), 1st drying (1D) and 2nd drying (2D) stages of the process (Table 2). Model systems were prepared in $0.2 \mathrm{mM}$ phosphate buffer, and their composition included nitrate, nitrite, $\mathrm{NaCl}$, sodium ascorbate and glucose at the concentrations included in Table 3. $\mathrm{a}_{\mathrm{w}}$ of the model systems at the different processing stages was adjusted with glycerol. Sterilization was performed by filtration using a $0.2 \mu \mathrm{m}$ filter (Sartorius, Göttingen, Germany), and incubation of the three model systems was performed at 25 and $37^{\circ} \mathrm{C}$. The experiments were performed in triplicate. Samples from each media and temperature were taken at $0,5,11,15,20,25,29$ and 35 days for physicochemical analysis, volatiles and amino acid composition. 
Table 2. Composition in amino acids ( $\mathrm{mg} / 100 \mathrm{~mL}$ ) of each model system according to the concentration of amino acids reported in different ripening stages of dry fermented sausages $[40,41]$.

\begin{tabular}{cccc}
\hline Amino Acids & Initial Stage & 1st Drying Stage & 2nd Drying Stage \\
\hline Ala & 29.91 & 91.85 & 111.80 \\
Gly & 10.94 & 33.06 & 42.58 \\
Val & 6.01 & 72.05 & 90.35 \\
B-Ala & 3.48 & 4.35 & 4.54 \\
Leu & 5.96 & 151.80 & 176.80 \\
Ile & 4.17 & 45.49 & 62.08 \\
Thr & 4.55 & 35.15 & 54.99 \\
Ser & 4.72 & 31.96 & 19.24 \\
Pro & 4.26 & 83.60 & 89.05 \\
Asn & 1.40 & 14.74 & 21.71 \\
Asp & 16.67 & 106.70 & 100.10 \\
Met & 2.00 & 33.99 & 36.27 \\
Glu & 10.53 & 74.25 & 73.45 \\
Phe & 3.82 & 70.95 & 83.85 \\
Gln & 36.47 & 64.90 & 65.00 \\
Orn & 0.23 & 23.10 & 31.01 \\
Lys & 6.82 & 77.55 & 120.90 \\
His & 2.76 & 27.34 & 38.48 \\
Tyr & 4.47 & 29.21 & 26.98 \\
Trp & 1.34 & 16.89 & 17.03 \\
C-C & 2.53 & 3.22 & 5.36 \\
Arg & 8.30 & 5.29 & 9.49 \\
Cys & 4.03 & 10.40 & 11.12 \\
\hline
\end{tabular}

Table 3. Physicochemical conditions of the model systems simulating the ripening stages in the production of dry fermented sausages.

\begin{tabular}{cccc}
\hline Dry Curing Stages & Initial Stage & 1st Drying Stage & 2nd Drying Stage \\
\hline $\mathrm{pH}$ & 5.45 & 4.38 & 4.60 \\
Glycerol $(\mathrm{ml} / 100 \mathrm{~mL})$ & 0 & 9 & 23 \\
$\mathrm{a}_{\mathrm{w}}$ & 0.968 & 0.944 & 0.895 \\
$\mathrm{NaCl}(\mathrm{mg} / \mathrm{mL})$ & 27 & 27 & 27 \\
$\mathrm{NaNO}_{2}(\mathrm{mg} / \mathrm{mL})$ & 0.15 & 0 & 0 \\
$\mathrm{NaNO}_{3}(\mathrm{mg} / \mathrm{mL})$ & 0.15 & 0.10 & 0.075 \\
Sodium ascorbate $(\mathrm{mg} / \mathrm{mL})$ & 0.5 & 0.5 & 0.5 \\
Glucose $(\mathrm{mg} / \mathrm{mL})$ & 20 & 5 & 5 \\
Amino acids $(\mathrm{mg} / 100 \mathrm{~mL})$ & Table 2 & Table 2 & Table 2 \\
& (Initial stage) & (1st drying stage) & (2nd drying stage) \\
\hline
\end{tabular}

\subsection{Analysis of Water Activity and $p H$}

Water activity $\left(\mathrm{a}_{\mathrm{w}}\right)$ was measured using an AQUALAB ${ }^{\circledR} 4$ Water Activity Meter (METER Group, München, Germany), and $\mathrm{pH}$ was measured using a pH-meter (Orion EA 920, Boston, MA, USA).

\subsection{Analysis of Volatile Compounds}

Analysis of volatile compounds was carried out by headspace (HS) solid-phase microextraction (SPME) with an $85 \mu \mathrm{m}$ carboxen/polydimethylsiloxane (CAR/PDMS) fiber (Supelco, Bellefonte, PA, USA) using a gas chromatograph (Agilent HP 7890 series II, Hewlett-Packard, Palo Alto, CA, USA) with a quadrupole mass detector (HP 5975C, Hewlett-Packard, Palo Alto, CA, USA). In summary, $5 \mathrm{~mL}$ of the model system was placed into a headspace vial using an automatic injector Gerstel MPS2 (Gerstel, Germany) [15] and incubated at $37^{\circ} \mathrm{C}$ for $30 \mathrm{~min}$. The extracted volatile compounds were adsorbed in the fiber for $60 \mathrm{~min}$ at $30^{\circ} \mathrm{C}$ and desorbed in the injection port of the GC-MS for $5 \mathrm{~min}$ at $240{ }^{\circ} \mathrm{C}$ in splitless mode. The volatile compounds were separated using a DB-624 capillary 
column (30 m, $0.25 \mathrm{~mm}$ i.d., film thickness $1.4 \mu \mathrm{m}$ (J\&W Scientific, Agilent Technologies, Palo Alto, CA, USA)) using the conditions described by Corral et al. [42]. The MS interface temperature was set to $240{ }^{\circ} \mathrm{C}$. The compounds were identified in full scan mode and by comparison with mass spectra from the library database (Nist'05), with linear retention indices [43] and using authentic standards. The quantitation was performed in SCAN mode using either total ion current (TIC) on an arbitrary scale and expressed as abundance units $(\mathrm{AU}) \times 10^{6}$.

\subsection{Analysis of Amino Acids}

The analysis of free amino acids was performed using the EZ-Faast kit from Phenomenex (Torrance, CA, USA). Model system samples were diluted at ratio 1:5 $(v / v)$ for I stage, and 1:25 $(v / v)$ for $1 \mathrm{D}$ and $2 \mathrm{D}$ stages with distilled water previously to derivatization. The derived amino acids were analyzed using GC-FID. A gas chromatograph (Agilent Technologies 7890B) with a flame ionization detector (FID) equipped with an autosampler G4513A and a ZB-AAA $10 \mathrm{~m} \times 0.25 \mathrm{~mm}$ GC column (Phenomenex) was used. The injection volume was $2.5 \mu \mathrm{L}$ at $250{ }^{\circ} \mathrm{C}$ in split mode (15:1). Helium was used as a carrier gas at a constant flow of $27 \mathrm{~mL} / \mathrm{min}$ during the run, and the column head pressure was 8.78 psi. The GC oven temperature was initially held at $110{ }^{\circ} \mathrm{C}$ and then raised to $320^{\circ} \mathrm{C}$ at $32{ }^{\circ} \mathrm{C} / \mathrm{min}$; the inlet temperature was $250{ }^{\circ} \mathrm{C}$, and the detector was set at $320^{\circ} \mathrm{C}$. Identification and quantification were based on retention time and peak area integration of the reference amino acids. Norleucine was used as the internal standard. Calibration curves for each amino acid were obtained with the standard amino acids solutions (Phenomenex). In addition, several amino acids were prepared at high concentrations to adjust the calibration curves to the levels present in media samples. Results were expressed in milligrams per $100 \mathrm{~mL}$ of model system.

\subsection{Statistical Analyses}

The effect of different model system composition and incubation time on the generation of volatile compounds were tested by two-factor analysis of variance (ANOVA) at each temperature $\left(25\right.$ and $\left.37^{\circ} \mathrm{C}\right)$ using the statistic software XLSTAT2018 (Addinsoft, Barcelona, Spain). The effect of temperature and time on the amino acid content was studied in each media by a two-factor analysis of variance (ANOVA). Significant differences between samples means were analyzed according to Tukey test $(p<0.05)$. Principal component analysis (PCA) was plotted to evaluate the relationships among the different ripening stages, incubation temperature and volatile compounds in model systems measured at each sampling time.

\section{Conclusions}

This study has shown high yields of volatile compounds produced in model systems resembling dry fermented meat products at different curing stages in terms of amino acid content, $\mathrm{pH}$, lower $\mathrm{a}_{\mathrm{w}}$ and temperature $\left(37 \mathrm{vs.} 25^{\circ} \mathrm{C}\right.$ ). In order to improve the formation of aroma compounds during the ripening process, the increase in temperature during dry curing process would favor their generation once the $\mathrm{a}_{\mathrm{w}}$ value is low and amino acid concentration increases from the proteolytic activity. This research demonstrates that in dry fermented meat products, free amino acids participate in the generation of volatile compounds via the Maillard reaction in addition to the microbial activity. Moreover, $\mathrm{a}_{\mathrm{w}}$ and temperature play an important role in these processes promoting the formation of flavor compounds in dry cured meat products.

Supplementary Materials: The following are available online. Figure S1: Changes in aw of the model systems during incubation at 25 or $37^{\circ} \mathrm{C}$ simulating the dry curing stages (I-Initial stage, 1D-1st drying stage, 2D-2nd drying stage). Figure S2: Changes in $\mathrm{pH}$ of the model systems during incubation at 25 or $37^{\circ} \mathrm{C}$ simulating the dry curing stages (I-Initial stage, 1D-1st drying stage, 2D-2nd drying stage). Table S1: Volatile compounds produced at $25^{\circ} \mathrm{C}$ in the model systems simulating the dry curing stages (expressed as abundance $(\mathrm{AU})$ of total ion current (TIC) as AU $\times 106$ ). Table S2: 
Volatile compounds produced at $37^{\circ} \mathrm{C}$ in the model systems simulating the dry curing stages (expressed as abundance (AU) of total ion current (TIC) as AU $\times 106)$. Table S3: Concentration of amino acids $(\mathrm{mg} / 100 \mathrm{~mL})$ in the model systems simulating the dry curing stages.

Author Contributions: L.L. carried out the experiments and wrote the manuscript with support from C.B. and M.F.; C.B. and M.F. supervised the project and contributed to the design and analysis of the results. All authors have read and agreed to the published version of the manuscript.

Funding: This research was funded by RTI2018-098074-B-I00 (MCIU/AEI/FEDER) from Spain and the financial support to Lei Li from Henan University of Animal Husbandry and Economy in China.

Institutional Review Board Statement: Not applicable.

Informed Consent Statement: Not applicable.

Data Availability Statement: Data is contained within the article or supplementary material.

Acknowledgments: The authors are grateful to J.J. López-Díez for technical assistance.

Conflicts of Interest: The authors declare no conflict of interest. The funders had no role in the design of the study; in the collection, analyses, or interpretation of data; in the writing of the manuscript, or in the decision to publish the results.

Sample Availability: Samples of the compounds are available from the authors.

\section{References}

1. Flores, M. Understanding the implications of current health trends on the aroma of wet and dry cured meat products. Meat Sci. 2018, 144, 53-61. [CrossRef]

2. Toldrá, F.; Flores, M. Section XIII. Meat and meat products: Processed pork meat flavors. In Handbook of Food Products Manufacturing; John Wiley \& Sons, Ltd.: Hoboken, NJ, USA, 2006; Volume 2, pp. 281-301. ISBN 9780470049648.

3. Resconi, V.C.; Escudero, A.; Campo, M.M. The development of aromas in ruminant meat. Molecules 2013, 18, 6748-6781. [CrossRef]

4. Chiang, J.H.; Eyres, G.T.; Silcock, P.J.; Hardacre, A.K.; Parker, M.E. Changes in the physicochemical properties and flavour compounds of beef bone hydrolysates after Maillard reaction. Food Res. Int. 2019. [CrossRef]

5. Van Boekel, M.A.J.S. Formation of flavour compounds in the Maillard reaction. Biotechnol. Adv. 2006, 24, 230-233. [CrossRef]

6. Mottram, D.S. Flavour formation in meat and meat products: A review. Food Chem. 1998. [CrossRef]

7. Elmore, J.S.; Campo, M.M.; Enser, M.; Mottram, D.S. Effect of lipid composition on meat-like model systems containing cysteine, ribose, and polyunsaturated fatty acids. J. Agric. Food Chem. 2002. [CrossRef]

8. Zhao, J.; Wang, T.; Xie, J.; Xiao, Q.; Du, W.; Wang, Y.; Cheng, J.; Wang, S. Meat flavor generation from different composition patterns of initial Maillard stage intermediates formed in heated cysteine-xylose-glycine reaction systems. Food Chem. 2019. [CrossRef]

9. Hou, L.; Xie, J.; Zhao, J.; Zhao, M.; Fan, M.; Xiao, Q.; Liang, J.; Chen, F. Roles of different initial Maillard intermediates and pathways in meat flavor formation for cysteine-xylose-glycine model reaction systems. Food Chem. 2017. [CrossRef]

10. Koutsidis, G.; Elmore, J.S.; Oruna-Concha, M.J.; Campo, M.M.; Wood, J.D.; Mottram, D.S. Water-soluble precursors of beef flavour. Part II: Effect of post-mortem conditioning. Meat Sci. 2008. [CrossRef]

11. Toldrá, F. Chapter 9-The storage and preservation of meat: III-Meat processing. In Lawrie's Meat Science, 8th ed.; Toldra, F., Ed.; Woodhead Publishing Series in Food Science, Technology and Nutrition; Woodhead Publishing: Cambridge, UK, 2017; pp. 265-296, ISBN 978-0-08-100694-8.

12. Toldrá, F. Characterization of Proteolysis. In Dry-Cured Meat Products; John Wiley \& Sons, Ltd.: Hoboken, NJ, USA, 2008; pp. 113-134, ISBN 9780470385111.

13. Modi, V.K.; Linforth, R.; Taylor, A.J. Effect of $\mathrm{pH}$ and water activity in generation of selected meaty aroma compounds in a meat model system. Am. J. Food Technol. 2008, 3, 68-78. [CrossRef]

14. Flores, M.; Olivares, A. Flavor. In Handbook of Fermented Meat and Poultry, 2nd ed.; John Wiley \& Sons, Ltd.: Hoboken, NJ, USA, 2014; pp. 217-225. ISBN 9781118522653.

15. Cano-García, L.; Rivera-Jiménez, S.; Belloch, C.; Flores, M. Generation of aroma compounds in a fermented sausage meat model system by Debaryomyces hansenii strains. Food Chem. 2014, 151. [CrossRef]

16. Marco, A.; Navarro, J.L.; Flores, M. The influence of nitrite and nitrate on microbial, chemical and sensory parameters of slow dry fermented sausage. Meat Sci. 2006. [CrossRef]

17. Martins, S.I.F.S.; Jongen, W.M.F.; Van Boekel, M.A.J.S. A review of Maillard reaction in food and implications to kinetic modelling. Trends Food Sci. Technol. 2000, 11, 364-373. [CrossRef]

18. Limacher, A.; Kerler, J.; Davidek, T.; Schmalzried, F.; Blank, I. Formation of furan and methylfuran by maillard-type reactions in model systems and food. J. Agric. Food Chem. 2008, 56. [CrossRef]

19. Beck, H.C.; Hansen, A.M.; Lauritsen, F.R. Metabolite production and kinetics of branched-chain aldehyde oxidation in Staphylococcus xylosus. Enzyme Microb. Technol. 2002, 31, 94-101. [CrossRef] 
20. Wolle, D.D.; Banavara, D.S.; Rankin, S.A. Short communication: Empirical and mechanistic evidence for the role of pyridoxal-5'phosphate in the generation of methanethiol from methionine. J. Dairy Sci. 2006, 89, 4545-4550. [CrossRef]

21. De Revel, G.; Marchand, S.; Bertrad, A. Identification of Maillard-Type Aroma Compounds in Winelike Model Systems of CysteineCarbonyls: Occurrence in Wine; American Chemical Society: Washington, DC, USA, 2003; pp. 353-364.

22. Meynier, A.; Mottram, D.S. The effect of $\mathrm{pH}$ on the formation of volatile compounds in meat-related model systems. Food Chem. 1995, 52, 361-366. [CrossRef]

23. Van Lancker, F.; Adams, A.N.; De Kimpe, N. Formation of pyrazines in maillard model systems of lysine-containing dipeptides. J. Agric. Food Chem. 2010. [CrossRef]

24. Mandin, O.; Duckham, S.C.; Ames, J.M. Volatile compounds from potato-like model systems. J. Agric. Food Chem. 1999, 47, 2355-2359. [CrossRef]

25. Hidalgo, F.J.; Zamora, R. Formation of phenylacetic acid and benzaldehyde by degradation of phenylalanine in the presence of lipid hydroperoxides: New routes in the amino acid degradation pathways initiated by lipid oxidation products. Food Chem. $X$ 2019, 2. [CrossRef]

26. Tabanelli, G.; Coloretti, F.; Chiavari, C.; Grazia, L.; Lanciotti, R.; Gardini, F. Effects of starter cultures and fermentation climate on the properties of two types of typical Italian dry fermented sausages produced under industrial conditions. Food Control 2012. [CrossRef]

27. Zamora, R.; Hidalgo, F.J. The Maillard reaction and lipid oxidation. Lipid Technol. 2011, 23, 59-62. [CrossRef]

28. Petersen, C.D.V.; Beck, H.C.; Lauritsen, F.R. On-line monitoring of important organoleptic methyl-branched aldehydes during batch fermentation of starter culture staphylococcus xylosus reveal new insight into their production in a model fermentation. Biotechnol. Bioeng. 2004, 85, 298-305. [CrossRef] [PubMed]

29. Balagiannis, D.P.; Parker, J.K.; Pyle, D.L.; Desforges, N.; Wedzicha, B.L.; Mottram, D.S. Kinetic modeling of the generation of 2and 3-methylbutanal in a heated extract of beef liver. J. Agric. Food Chem. 2009. [CrossRef] [PubMed]

30. Eichner, K.; Karel, M. The influence of water content and water activity on the sugar-amino browning reaction in model systems under various conditions. J. Agric. Food Chem. 1972, 20, 218-223. [CrossRef]

31. Majcher, M. Saccharides-derived flavor compounds. In Food Flavors: Chemical, Sensory and Technological Properties; CRC Press: Boca Raton, FL, USA, 2011; pp. 95-120. ISBN 9781439814925.

32. Toldrá, F.; Flores, M. Dry and semidry. In Encyclopedia of Meat Sciences; Academic Press: Cambridge, MA, USA, 2014; ISBN 9780123847317.

33. Perea-Sanz, L.; Peris, D.; Belloch, C.; Flores, M. Debaryomyces hansenii metabolism of sulfur amino acids as precursors of volatile sulfur compounds of interest in meat products. J. Agric. Food Chem. 2019. [CrossRef]

34. Martins, S.I.F.S.; Van Boekel, M.A.J.S. A kinetic model for the glucose/glycine Maillard reaction pathways. Food Chem. 2005, 90, 257-269. [CrossRef]

35. Pripi-Nicolau, L.; De Revel, G.; Bertrand, A.; Maujean, A. Formation of flavor components by the reaction of amino acid and carbonyl compounds in mild conditions. J. Agric. Food Chem. 2000. [CrossRef]

36. Zhu, C.Z.; Zhao, J.L.; Tian, W.; Liu, Y.X.; Li, M.Y.; Zhao, G.M. Contribution of histidine and lysine to the generation of volatile compounds in Jinhua ham exposed to ripening conditions via Maillard reaction. J. Food Sci. 2018, 83, 46-52. [CrossRef]

37. Olivares, A.; Navarro, J.L.; Flores, M. Distribution of volatile compounds in lean and subcutaneous fat tissues during processing of dry fermented sausages. Food Res. Int. 2009. [CrossRef]

38. Marco, A.; Navarro, J.L.; Flores, M. Volatile compounds of dry-fermented sausages as affected by solid-phase microextraction (SPME). Food Chem. 2004. [CrossRef]

39. Olivares, A.; Navarro, J.L.; Flores, M. Characterization of volatile compounds responsible for the aroma in naturally fermented sausages by gas chromatography-olfactometry. Food Sci. Technol. Int. 2015. [CrossRef] [PubMed]

40. Olivares, A.; Navarro, J.L.; Salvador, A.; Flores, M. Sensory acceptability of slow fermented sausages based on fat content and ripening time. Meat Sci. 2010, 86, 251-257. [CrossRef]

41. Corral, S.; Leitner, E.; Siegmund, B.; Flores, M. Determination of sulfur and nitrogen compounds during the processing of dry fermented sausages and their relation to amino acid generation. Food Chem. 2016, 190, 657-664. [CrossRef]

42. Corral, S.; Salvador, A.; Belloch, C.; Flores, M. Improvement the aroma of reduced fat and salt fermented sausages by Debaromyces hansenii inoculation. Food Control 2015, 47, 526-535. [CrossRef]

43. Van Den Dool, H.; Kratz, P.D. A generalization of the retention index system including linear temperature programmed gas-liquid partition chromatography. J. Chromatogr. A 1963, 11, 463-471. [CrossRef] 